\title{
A interculturalidade no ensino de PLE: metodologias ativas e políticas linguísticas
}

DOI: http://dx.doi.org/10.21165/el.v48i3.2220

\section{Gabriele Franco'}

\section{Resumo}

A formação de professores de português como língua estrangeira (PLE) possui um papel importante no ensino e na aprendizagem como um todo, sobretudo no ensino intercultural. O PLE, em seus diferentes contextos educacionais, lida com um público-alvo diverso e tem o desafio de desenvolver as condições necessárias para a compreensão de uma nova língua e cultura. No entanto, além de capacitar professores de PLE, é preciso oferecer uma formação intercultural que deve ser evidenciada por políticas linguísticas que viabilizem a elaboração de documentos norteadores e de metodologias para a atuação docente. Por isso, o presente trabalho reflete sobre a abordagem que as políticas linguísticas e os documentos orientadores como a Lei de Diretrizes e Bases (LDB), o Plano Nacional da Educação (PNE), o Parâmetro Curricular Nacional (PCN), as Orientações Curriculares para o Ensino Médio (OCEM), as Diretrizes Curriculares Nacionais da Educação Básica (DCN), a Base Nacional Comum Curricular (BNCC) e as Diretrizes Curriculares Nacionais para os cursos de graduação propõem para um ensino intercultural. Além disso, apresentase uma proposta para uma educação intercultural no ensino de português como língua estrangeira por meio da metodologia de Aprendizagem Baseada em Projetos (ABP).

Palavras-chave: interculturalidade; português como língua estrangeira; políticas linguísticas; aprendizagem baseada em projetos.

1 Universidade de São Paulo (USP), São Paulo, São Paulo, Brasil; gabrielefranco@usp.br; https://orcid.org/0000-0001-6580-4796 


\title{
Interculturality in PFL teaching: active methodologies and linguistic policies
}

\begin{abstract}
The teachers' training of Portuguese as a foreign language (PFL) plays an important role in the teaching-learning process as a whole, mainly in the intercultural education, because different contexts of teaching-learning of PLE deal with a diverse target audience, and they are responsible for developing the necessary conditions for understanding the target language and culture. However, in addition to training PLE teachers, it is necessary to offer an intercultural training which should be evidenced by linguistic policies that enable the elaboration of guiding documents and methodologies for practicing teaching. Because of that, this article reflects upon the approaching that linguistic politics and guideline documents, such as Lei de Diretrizes e Bases (LDB), the Plano Nacional da Educação (PNE), the Parâmetro Curricular Nacional (PCN), the Orientações Curriculares para o Ensino Médio (OCEM), the Diretrizes Curriculares Nacionais da Educação Básica (DCN), the Base Nacional Comum Curricular (BNCC) and the Diretrizes Curriculares Nacionais para os cursos de Graduação can offer for the interculturality and to promote it in the teaching of Portuguese as a foreign language by the methodology of Project-Based Learning (PBL).
\end{abstract}

Keywords: interculturality; Portuguese as a foreign language; language policies; projectbased learning.

\section{Introdução}

Diante dos desafios impostos pelo fenômeno migratório do século XXI, um aprendiz de línguas estrangeiras precisa ser multilíngue e multicultural. A globalização e as políticas de internacionalização viabilizam contato entre as culturas, mas nem sempre estabelecem uma relação crítica entre elas. O reconhecimento da existência de outros povos e línguas já não é suficiente para estabelecer relações interpessoais, pois a contemporaneidade pressupõe a leitura da realidade através de uma perspectiva altruísta que favoreça as relações interculturais. Nesse sentido, a alteridade pode ser o caminho para o futuro, como sugere Clarice Lispector (1999, p. 119): "Mas sei de uma coisa: meu caminho não sou eu, é o outro, são os outros. Quando eu puder sentir plenamente o outro estarei salva e pensarei: eis o meu porto de chegada".

Os deslocamentos migratórios não são fenômenos novos e exclusivos da globalização, fazem parte da história humana. Em todas as épocas, as migrações levantaram desafios para os países, as sociedades locais ou regionais e para a comunidade internacional. Porém, em cada contexto histórico, esses desafios se configuraram de forma diferenciada. A princípio, os países colonizadores dirigiam-se às colônias com a finalidade de explorar, como é o caso do Brasil, o qual pertenceu aos reinos de Portugal e da Espanha. Nesse 
contexto, a dominação cultural foi estabelecida pela violência física e pela imposição de novos costumes e línguas.

No século $X X I$, o fenômeno migratório constitui um espelho das assimetrias das relações socioeconômicas vigentes em nível planetário. São termômetros que apontam as contradições das relações internacionais e da globalização neoliberal. Além disso, por sua intensidade e diversificação, torna-se cada vez mais complexo, principalmente porque atua em diferentes sentidos. Os antigos colonizadores recebem imigrantes de suas ex-colônias, como ocorre nas relações entre Brasil, Espanha e Portugal. Entretanto, as relações culturais, muitas vezes, são desiguais, pois uma cultura se impõe enquanto a outra é renegada. De um lado, a globalização intensificou o contato entre culturas nas sociedades contemporâneas por meio das facilidades tecnológicas que colocam diferentes universos em contato. Por outro lado, o estreitamento das relações culturais nem sempre ocorre a partir da alteridade e renascem as exigências de identidade local que podem gerar conflitos e preconceitos quando mal administradas.

Nesse sentido, a educação e, sobretudo, a formação de professores de português para estrangeiros (PLE), possui um papel importante, pois lidam com um público-alvo diverso e responsabilizam-se por desenvolver as condições necessárias para a compreensão da língua e cultura-alvo. Posto que, além de formar professores de PLE, é preciso oferecer uma formação intercultural que deve ser evidenciada por políticas linguísticas que viabilizem a elaboração de documentos norteadores para a formação e a prática docente. Portanto, o presente trabalho levanta e investiga as seguintes questões: Como as políticas linguísticas e os documentos orientadores, como a Lei de Diretrizes e Bases (LDB), o Plano Nacional da Educação (PNE), o Parâmetro Curricular Nacional (PCN), as Orientações Curriculares para o Ensino Médio (OCEM), as Diretrizes Curriculares Nacionais da Educação Básica (DCN), a Base Nacional Comum Curricular (BNCC) e as Diretrizes Curriculares Nacionais para os cursos de Graduação, consideram o tema da interculturalidade? Como promover a prática intercultural para o ensino de português como língua estrangeira?

\section{Multi, pluri ou intercultural?}

Para aprimorar a precisão terminológica dos conceitos, foi selecionado o aporte teórico utilizado por Márcia Paraquett (2010) e por García Martínez, Escarbajal Frutos e Escarbaral de Haro (2007), que abordam a ideia de multi, pluri e intercultural. Eles definem multiculturalismo como a ausência de convivência entre culturas diferentes em um mesmo espaço. O pluriculturalismo pressupõe apenas a co-presença de várias culturas em determinado espaço, mas não efetiva uma relação entre elas e ressaltamse as diferenças. Trata-se de um movimento que segrega e atua como consequência da globalização. A interculturalidade é uma inter-relação de diferentes culturas que convivem no mesmo espaço e estabelecem uma relação de interdependência: 
A interculturalidade também deve ser entendida como a habilidade para reconhecer, harmonizar e negociar as inumeráveis formas de diferença que existem na sociedade. Desse modo, a interculturalidade constitui um meio fundamental para desenvolver valores democráticos e responsabilidade política. Para isso, é fundamental fomentar a competência comunicativa intercultural. (GARCÍA MARTÍNEZ; ESCARBAJAL FRUTOS; ESCARBARAL DE HARO, 2007, p. 91-92).

A interculturalidade permite a reflexão sobre aspectos da língua, cultura e sociedade, itens indissociáveis, cabendo ao ensino de línguas o papel de viabilizar e de representar uma imagem do mundo em que se espelham diferentes realidades. Trata-se de uma característica que pode ser desenvolvida e pressupõe a capacidade de sentir-se como o outro, mesmo que ele seja completamente diferente, compartilhando e cooperando com ele. No contexto específico do ensino de PLE, essa habilidade pressupõe que o aluno saiba se comunicar de forma saudável com outras culturas, em uma relação de igualdade, sem hierarquia. Para isso, é necessário o desenvolvimento de inteligências múltiplas, pois esse processo resvala diretamente no desenvolvimento intercultural. Esse conceito está além da dimensão afetiva, trata-se da habilidade de empatia cultural que permite a troca de experiência, o desenvolvimento cooperativo e o pertencimento ao contexto do outro.

O desafio da formação intercultural está no fato de que necessariamente tem início com o professor. Segundo Dias (2016, p. 24), as percepções dos professores sobre a sua própria interculturalidade e a dimensão da sua própria capacidade reflexiva podem influenciar o desenvolvimento do aluno:

Nota-se que para que professores promovam a educação intercultural, devem eles próprios adquirir primeiro uma competência comunicativa intercultural (CCl). Esta competência pode ser fruto de um processo de formação claramente orientado para a sua aquisição e permite-Ihes promover a criação de contextos amigáveis que possibilitem a expressão, a descrição, a aceitação, o questionamento a busca e a integração de diversos modos de actuar, sentir, ser e pensar por parte dos alunos. (DIAS, 2016, p. 15).

Dessa forma, a interculturalidade oferece oportunidades para examinar e comparar diferentes valores, auxiliando os alunos a revisitar suas ideias em relação ao outro e a si, motivando-os e aumentando a sua compreensão de mundo. A identidade cultural da língua estrangeira precisa ser trabalhada de forma que o aprendiz valha-se dela para intensificar o seu processo de pertencimento cultural na sociedade em que está inserido. Essas são condições necessárias nas aulas de PLE, pois abrigam turmas heterogêneas, compostas por um público-alvo de diferentes culturas, faixa etária ou nível de proficiência. Além disso, muitas vezes, o ensino é direcionado para imigrantes refugiados de guerras, ditaduras ou catástrofes naturais. Isso implica que esses indivíduos precisam aprender 
normas, valores, costumes, o que só pode acontecer no contato com o outro. Por isso, a identidade é construída no diálogo com outras pessoas e outras culturas.

Portanto, somente um professor preparado pode administrar situações de conflito e propiciar o desenvolvimento da competência intercultural nos alunos. No entanto, a formação de professores para este desafio requer o suporte de políticas públicas e documentos orientadores. Pode-se dizer que já existe uma produção significativa sobre multiculturalismo e intercultura, evidenciando uma tendência crescente de pesquisas sobre os temas. Uma análise das políticas educacionais e da legislação pós-LDB confirma essa mesma tendência.

\section{De que forma o conceito de interculturalidade foi concebido e incorporado nos documentos orientadores e nas políticas educacionais?}

Considerando o Brasil no contexto global, nota-se que não possuímos políticas linguísticas e nem documentos norteadores para o ensino de nossa variedade de PLE especificamente para estrangeiros. Por isso, foram analisados os atuais documentos orientadores e as políticas educacionais do ensino básico e superior, como a Lei de Diretrizes e Bases (LDB), o Plano Nacional da Educação (PNE), o Parâmetro Curricular Nacional (PCN), as Orientações Curriculares para o Ensino Médio (OCEM), as Diretrizes Curriculares Nacionais da Educação Básica (DCN), a Base Nacional Comum Curricular (BNCC) e as Diretrizes Curriculares Nacionais para os cursos de Graduação. Embora não estejam direcionados ao ensino de PLE, os documentos foram analisados porque apresentam orientações de aprendizagem que compõem o repertório de todos os professores brasileiros, inclusive dos professores de PLE que não possuem parâmetros ou diretrizes específicas para a área.

Vale destacar que alguns destes documentos referem-se apenas ao ensino de PLE especificamente para surdos-mudos, indígenas e afrodescendentes. Segundo Telmo Marcon (2009), a legislação com diretrizes específicas para negros e indígenas com pareceres fundamentados pelo conceito de multi e intercultural foram elaboradas após a década de 1980. Nesse período, com a organização de vários movimentos sociais, ocorreram avanços substanciais que conduziram ao reconhecimento formal, na Constituição de 1988, de que a sociedade brasileira é plural.

A Lei de Diretrizes e Bases (LDB) faz referência ao ensino intercultural na educação de povos indígenas através dos artigos 78 e 79 . 0 artigo 78 designa a recuperação da memória histórica, reafırmação da identidade étnica e valorização das línguas indígenas, bem como a integração e o acesso destes povos à informação e conhecimentos técnicos da sociedade nacional. 0 artigo 79 oferece suporte e manutenção ao ensino intercultural, pois regulamenta o financiamento e organiza a elaboração de currículos, programas, bem como a publicação de material didático específico para a comunidade indígena: 
Art. 78. O Sistema de Ensino da União, com a colaboração das agências federais de fomento à cultura e de assistência aos índios, desenvolverá programas integrados de ensino e pesquisa, para oferta de educação escolar bilíngue e intercultural aos povos indígenas [...].

Art. 79. A União apoiará técnica e financeiramente os sistemas de ensino no provimento da educação intercultural às comunidades indígenas, desenvolvendo programas integrados de ensino e pesquisa.

No que diz respeito ao Plano Nacional de Educação (PNE, 2014) e às Diretrizes Curriculares Nacionais Gerais da Educação Básica (MEC, 2013), destaca-se o incentivo e a obrigatoriedade de conteúdos curriculares sobre a cultura afro-brasileira, bem como a perspectiva intercultural na educação indígena. As Diretrizes Nacionais dos Cursos de Graduação (MEC, 2001), especificamente o parecer CES/CNE 0146/2002 que determina as orientações para o curso de Letras, torna obrigatórios conteúdos curriculares que articulem a reflexão teórico-crítica "[...] de modo a dar prioridade à abordagem intercultural, que concebe a diferença como valor antropológico e como forma de desenvolver o espírito crítico frente à realidade [...]" (MEC, 2001, p. 31). Além disso, pode-se inferir que o perfil estabelecido como meta para a formação no curso complementa a proposta do conteúdo curricular, visto que:

[...] o objetivo do Curso de Letras é formar profissionais interculturalmente competentes, capazes de lidar, de forma crítica, com as linguagens, especialmente a verbal, nos contextos oral e escrito, e conscientes de sua inserção na sociedade e das relações com o outro. (MEC, 2001, p. 30).

Encontram-se referências ao ensino de PLE nos Parâmetros Curriculares Nacionais do Ensino Fundamental, na área de "Língua estrangeira". Contudo, não há menção ao ensino intercultural. Os objetivos gerais referem-se apenas à necessidade de sensibilizar o aluno para o mundo multicultural; observa-se que o termo "intercultural" ainda não foi empregado:

Os objetivos são orientados para a sensibilização do aluno em relação à Língua Estrangeira pelos seguintes focos: o mundo multilíngue e multicultural em que vive; a compreensão global (escrita e oral); o empenho na negociação do significado e não na correção. (PCN, 1998, p. 66).

Nos PCN de Língua Estrangeira para o Ensino Fundamental, o ensino do PLE é considerado apenas no contexto de alunos indígenas e comunidades de surdos. Entretanto, é apenas citado; não se desenvolve nenhuma estratégia ou orientação para a prática nesses casos específicos: 
Fatores relativos às comunidades locais: a convivência entre comunidades locais e imigrantes ou indígenas pode ser um critério para a inclusão de determinada língua no currículo escolar. Justifica-se pelas relações envolvidas nessa convivência: as relações culturais, afetivas e de parentesco. Por outro lado, em comunidades indígenas e em comunidades de surdos, nas quais a língua materna não é o português, justifica-se o ensino de Língua Portuguesa como segunda língua. (PCN, 1998, p. 23).

Além disso, os PCN para o Ensino Fundamental apresentam um anexo intitulado "Temas transversais: Pluralidade Cultural" que ressalta a importância de um levantamento de dados como mecanismos de resistência diante das tentativas de homogeneização:

Levantamento, análise e valorização da contribuição das diversas heranças etnoculturais, como mecanismos de resistência ante as políticas explícitas de homogeneização da população havidas no passado. (PCN, 1998, p. 154).

Valorização do ponto de vista dos grupos sociais para a compreensão dos processos culturais envolvidos na formação da população brasileira. (PCN, 1998, p. 155).

Conhecimento, respeito e valorização das diferentes linguagens pelas quais se expressa a pluralidade cultural. (PCN, 1998, p. 156).

Os Parâmetros Curriculares do Ensino Fundamental (PCN, 1988) exploram a questão de modo deficitário, pois, ainda que o documento recomende a busca e a valorização das heranças etnoculturais, aborda o processo de homogeneização como um problema do passado, ignorando que um ensino intercultural se justifica e se faz necessário devido a processos de homogeneização ainda latentes. Além disso, o documento limitase a apresentar tópicos que sugerem conteúdos, bem como a identificação de novas culturas, as diferenças e semelhanças entre elas com a finalidade de justificar um ensino a partir da pluralidade cultural. Os Parâmetros Curriculares Nacionais do Ensino Médio (PCNEM, 2000) apenas referem-se à obrigatoriedade que a LDB determina para o ensino intercultural destinado às comunidades indígenas.

Nas "Orientações Curriculares para o Ensino Médio (OCEM) - Linguagens, códigos e suas tecnologias", há um item de orientações pedagógicas para o ensino de espanhol que valoriza a comunicação intercultural para o desenvolvimento da consciência intercultural:

[...] ter consciência, entender e aceitar esses novos valores e crenças presentes em diferentes grupos sociais, distintos dos nossos em muitos aspectos, é imprescindível para que se efetive o que se vem chamando de comunicação intercultural (OCEM, 2006, p. 148). 
[...] A partir do momento em que o estudante desenvolve tais competências e habilidades de forma integrada, desenvolve-se também sua consciência intercultural. Dessa forma, um amplo tema gerador pode levar a reflexões de ordem bastante variada: lingüística, sociocultural, sócio-econômica, política, discursiva etc. (OCEM, 2006, p. 152).

Vale destacar que a segunda versão da proposta preliminar da Base Nacional Comum Curricular (BNCC, MEC, 2016) ressalta a interculturalidade além da questão indígena (2016, p. 17) e propõe uma abordagem intercultural em diversas disciplinas como Arte (2016, p. 193), Língua Inglesa (2016, p. 262), Geografia (2016, p. 390), Ensino Religioso (2016, p. 437) e também na área de Ciências Humanas e Sociais Aplicadas - integrada por Filosofia, Geografia, História e Sociologia (2016, p. 561). Além disso, há uma preocupação em relação à educação de crianças e jovens que vivem na fronteira com outros países. O documento (2016, p. 71) cita o Programa Escolas Interculturais de Fronteira (PEIF) que se desenvolve no âmbito do MERCOSUL, em cidades brasileiras da faixa de fronteira e em suas respectivas cidades-gêmeas de países fronteiriços ao Brasil. O objetivo do PEIF é promover a integração regional por meio da educação intercultural, garantindo formação integral nestas regiões de fronteira do Brasil com outros países, com atenção especial para os usos linguísticos. Na BNCC (2016), a dimensão intercultural torna-se um eixo dos conhecimentos linguísticos no ensino de Língua Inglesa ao lado da oralidade, leitura e escrita:

EIXO CONHECIMENTOS LINGUÍSTICOS - Práticas de análise linguística para a reflexão sobre o funcionamento da língua inglesa, com base nos usos de linguagem trabalhados nos eixos Oralidade, Leitura, Escrita e Dimensão intercultural. (BNCC, 2016, p. 262).

EIXO DIMENSÃO INTERCULTURAL - Reflexão sobre aspectos relativos à interação entre culturas (dos alunos e aquelas relacionadas a demais falantes de língua inglesa), de modo a favorecer o convívio, o respeito, a superação de conflitos e a valorização da diversidade entre os povos. (BNCC, 2016, p. 262).

Portanto, as atuais políticas do Ministério da Educação estabelecem desafios e objetivos que promovem a interculturalidade, no entanto, são restritivas e ambíguas ao abordar este tema. Caracterizam-se como restritivas porque ainda não possuímos políticas linguísticas que viabilizem a produção de um documento norteador para o ensino de PLE e são ambíguas porque embora saliente-se a necessidade do desenvolvimento da competência intercultural, ainda há uma visão da multiculturalidade e da pluriculturalidade na ação docente, o que implica considerar a diversidade cultural sob uma perspectiva hegemônica que acolhe e/ou assimila outra cultura de menor influência. 
Quando o assunto é política educacional para o ensino de PLE, quem coloca as cartas na mesa é Portugal através do ponto 4, do Despacho n² 21.787/2005 ( $2^{a}$ série), de 28 de setembro de 2005, do Gabinete do Secretário de Estado Adjunto e da Educação, publicado no Diário da República - II Série, $n^{\circ}$ 200, de 18 de outubro de 2005 que viabilizou a elaboração do documento orientador analisado neste trabalho: o "Quadro de referência para ensino de português no estrangeiro" (GROSSO et al., 2011). Esse documento foi baseado no "Quadro Europeu Comum de Referências para as línguas" (Conselho da Europa, 2001) com a finalidade de orientar o ensino da variante portuguesa para estrangeiros. Esses documentos possuem tópicos específicos para o tema da interculturalidade e ressaltam a importância do conhecimento sociocultural:

Também no ensino do português, a abordagem intercultural é fulcral no sentido de favorecer o desenvolvimento harmonioso da personalidade do aprendente e da sua identidade, que não raramente está dividida entre duas culturas, dando uma resposta à experiência enriquecedora da alteridade em matéria da língua e da cultura. (GROSSO, 2011 et al., p. 13).

Os documentos orientadores portugueses consideram a abordagem intercultural um objetivo essencial no ensino de PLE e inserem também a necessidade de identificação de representações culturais: "Identificar símbolos ligados à cultura portuguesa; Identificar estereótipos ligados aos portugueses e à cultura portuguesa" (GROSSO et al., 2011). O documento propõe a conexão entre comunidades portuguesas e países de língua oficial portuguesa, contudo seus objetivos limitam-se a promover apenas a cultura de Portugal:

Num esforço para valorizar a sua importância estratégico-política no quadro internacional, o EPE estabelece a ligação às comunidades portuguesas e aos países de língua oficial portuguesa, concede apoio e reconhecimento às escolas portuguesas, a par da promoção da língua e da cultura portuguesa junto de falantes de outras línguas e de outros sistemas educativos. A importância e prestígio da língua e da cultura portuguesa como veículo de formação e comunicação são actualmente vectores fundamentais da acção política portuguesa no âmbito internacional. (GROSSO et al., 2011, p. 6).

Embora se ressalte um ensino baseado na alteridade, outras variedades da língua portuguesa são excluídas. O reconhecimento das variedades linguísticas e culturais implica compreender a língua numa perspectiva intercultural, redescobrindo diversas abordagens e renovados processos de ensino-aprendizagem. Além disso, esse distanciamento de outras variedades da língua portuguesa favorece a propagação de representações culturais inadequadas que podem remeter à relação hierárquica do período colonial, posto que o Brasil foi colônia de exploração de Portugal. 
Refletir sobre estas questões é de extrema importância. Entretanto, não basta criticar a perspectiva ambígua adotada por algumas políticas linguísticas ou a falta delas; é fundamental propor alternativas que sustentem o ensino intercultural, superando a ausência de políticas públicas e as tendências, sem sufocar o fragmento e o particular como princípios absolutos. A busca por um caminho que supere esses extremos tornouse um dos grandes desafios para uma educação emancipatória.

\section{Como promover uma prática intercultural para o ensino de português como língua estrangeira?}

A princípio, os alunos, sejam eles professores em formação ou não, elaboram opiniões, crenças, valores e estereótipos nacionais sobre a cultura da língua-alvo. Estas imagens que podem ser positivas, negativas, verdadeiras ou falsas são denominadas representações culturais (HALL, 1997). Para vivenciar a nova cultura com a consciência e a compreensão da diversidade como riqueza, o aluno reflete sobre as representações da cultura-alvo. Nesse sentido, o ensino da história de um país, as normas sociais, a geografia, o folclore e a literatura são fatores necessários para compreender outra cultura. Entretanto, explorar apenas esses tópicos no processo de ensino aprendizagem não é suficiente para desenvolver a competência intercultural.

A elaboração de uma "receita de sucesso" ou um manual específico para a efetivação de uma perspectiva intercultural de compreensão, comunicação e alteridade em língua estrangeira seria um paradoxo. No entanto, é possível propor caminhos para que professores e alunos desenvolvam conteúdos através de uma perspectiva integradora, com tópicos que sugerem e justificam o ensino a partir da abordagem intercultural. Dois tópicos destacam-se nesse contexto: o papel da tecnologia e o uso de metodologias inovadoras.

Nem sempre escolas de qualidade estão associadas à tecnologia de ponta; sobre este assunto Calvo (2015, p. 92, tradução nossa²) afirma que: "Uma boa pergunta para o século XXI é aquela cuja resposta não se pode <<googlear >>". A tecnologia é uma ferramenta muito importante para a aprendizagem, mas antes dela é preciso criatividade, metodologia, planejamento e relação constante entre o aprendizado e a realidade local/ global. Sendo assim, não se trata de possuir altos recursos e tecnologias, mas de desenvolver metodologias e práticas. A escola e a universidade devem ser movidas por questionamentos propostos pelos alunos, pois todo o processo de aprendizagem parte de suas motivações pessoais e das dificuldades do contexto que os cerca. A solução para os problemas e dificuldades do mundo atual e futuro não estão na internet, por isso precisamos de alunos capazes de conectar as diferentes áreas do conhecimento, já que a tecnologia não pode desempenhar essa função.

2 No original: "Una buena pregunta para el siglo XXI es aquella cuya respuesta no se pueda $<<$ googlear $>$ ". 
Nesse sentido, destacam-se as metodologias inovadoras, como a Aprendizagem Baseada em Projetos (ABP), que consiste na elaboração de projetos autênticos baseados em uma questão, tarefa ou problema para aprender conteúdos acadêmicos através do trabalho cooperativo. A ABP não deve partir apenas de um tema proposto por professores ou coordenação pedagógica, arbitrado por contextos externos aos alunos para satisfazer os conteúdos da disciplina. É preciso que os estudantes e professores, conjuntamente, sejam autores no processo de ensino aprendizagem, pois as atividades desenvolvidas se inserem no contexto real do aluno. Essas características Ihe outorgam um duplo significado: os projetos satisfazem as necessidades dos estudantes e as decisões não são hierárquicas, uma vez que são tomadas pelos docentes e discentes.

Como suporte teórico para a aplicação prática da ABP, que pode ser utilizado no ensino de PLE, destacam-se duas obras: Aprendizagem baseada em projeto - guia para professores de ensino fundamental e médio (2008), do Buck Institute for Education, e Aprendizagem Baseada em Projetos: Educação diferenciada para o século XXI (2014), de Willian Bender.

O enfoque da teoria ABP de Willian N. Bender (2014) é a aprendizagem cooperativa, pois essa ferramenta reflete melhor as demandas do ambiente de trabalho no século XXI do que as tarefas individuais de resolução de problemas. A aprendizagem cooperativa promove mudanças nas habilidades e nos papéis de docentes e discentes e requer transformações. Segundo Bender (2014), nos grupos de aprendizagem coletiva, os alunos familiarizam-se com o novo conteúdo e também aprendem importantíssimas habilidades necessárias ao mercado de trabalho no século XXI ao compartilharem experiências com colegas de origens diferentes, atividades culturais e níveis acadêmicos variados. Os discentes que participam desse paradigma de ensino aprendem a interagir de forma bem-sucedida com os demais, à medida que constroem e sintetizam informações para explicar novos conceitos e desenvolver soluções para problemas.

O autor ainda aponta que os alunos irão precisar do suporte do professor para desenvolver as habilidades de aprendizagem cooperativa, como o processamento em grupo, as habilidades interpessoais, o gerenciamento de conflitos e as estratégias para a tomada de decisões ou comunicação pessoal eficaz. Além disso, cada membro do grupo de aprendizagem cooperativa deve ser encorajado a compreender que o sucesso ou o fracasso do grupo dependem das contribuições de cada um e que todos devem lidar com as consequências, caso um dos integrantes não participe adequadamente da realização das tarefas. Posto isso, tanto a responsabilidade individual como do grupo deve ser enfatizada nas tarefas de aprendizagem cooperativa.

Em complemento à teoria ABP apresentada por Wllian N. Bender (2014), o Buck Institute for Education (2008) propõe uma abordagem PBL como um método extremamente sistemático de ensino que envolve os alunos na aquisição de conhecimentos e habilidades por meio de um extenso processo de investigação estruturado a questões complexas e autênticas e de produtos e tarefas cuidadosamente planejadas. Como o título já indica, 
o livro Aprendizagem baseada em projeto - guia para professores de ensino fundamental e médio (2008) é um manual para professores interessados em aplicar a metodologia PBL em sala de aula, onde se encontram roteiros, tabelas de avaliação e exemplos de projetos.

O manual ressalta a necessidade de formular projetos focados em padrões que reflitam a atual ênfase no conteúdo, na aprendizagem bem-sucedida e no desempenho. Seus projetos partem do conteúdo curricular e utilizam avaliações alinhadas para verificar o que os alunos aprenderam. São formulados a partir de uma questão norteadora que integra os resultados almejados às atividades do projeto. Incorporam atividades vitais ao ambiente de trabalho e hábitos de aprendizagem contínua, além de ajudar os professores a utilizar recursos da comunidade para ampliar os limites do projeto além das quatro paredes da sala de aula.

O método proposto por Bender (2014) e aquele proposto pelo Buck Institute for Education (2008) utilizam a Aprendizagem Baseada em Projeto através de diferentes abordagens, porém ambos podem ser adaptados e incorporados ao ensino de português como língua estrangeira tanto nos cursos de formação de professores, quanto nos cursos de língua estrangeira.

No contexto específico do PLE as turmas são heterogêneas, sendo assim não convém impor um currículo fechado e um material didático como se todos os alunos fossem iguais e aprendessem da mesma forma. 0 ensino conteudista focado na transferência de conteúdos não prepara o aluno de PLE para movimentar-se em nova cultura, nem para inserir-se na sociedade ou no mercado de trabalho, principalmente se este aluno é um professor em formação. Neste contexto, o uso de metodologias diferenciadas poderia alavancar o ensino intercultural, permitindo que o discente seja o centro da aprendizagem; seu papel não é reter conteúdo, mas construí-lo.

Aplicar novas metodologias, especialmente a ABP, é uma atividade com impacto em curto, médio e longo prazo. Em curto e médio prazo, serão cumpridos os objetivos específicos dos projetos elaborados e em longo prazo, o trabalho cooperativo pressupõe o desenvolvimento de habilidades interpessoais necessárias à competência intercultural. Além disso, a ABP permitirá que futuras gerações sejam estimuladas desde a escola a desenvolver habilidades e competências necessárias para transformar a realidade.

\section{Considerações finais}

Vale ressaltar que há uma preocupação em revolucionar a educação no Ensino Fundamental, Médio ou em escolas de idiomas. Contudo, as metodologias inovadoras devem chegar também à universidade, pois é um espaço de formação dos professores e estes profissionais possuem o desafio de introduzi-las na sala de aula e de fomentar a competência intercultural dos alunos. Talvez, antes de introduzir tecnologias, metodologias e práticas, seja importante investir na formação de profissionais 
comprometidos e competentes. Daí a importância do apoio de políticas educacionais e linguísticas, principalmente para a formação de docentes para o ensino da variedade brasileira de PLE.

Os professores portugueses de PLE já possuem este apoio político e teórico para uma formação e capacitação intercultural. Diante do cenário brasileiro, carente de políticas linguísticas que promovam o avanço da interculturalidade e o ensino de PLE para estrangeiros, apresenta-se um desafio de remodelar a postura de multiculturalidade e desenhar alguma política intercultural em que os docentes se formem para ensinar com ferramentas inovadoras os temas ligados à diversidade cultural. Portanto, a ação cooperativa entre as políticas linguísticas, a formação de professores e as metodologias inovadoras viabiliza o desenvolvimento da competência intercultural, favorecendo a formação de uma geração preparada para transformar realidades.

\section{REFERÊNCIAS}

BENDER, W. N. Aprendizagem Baseada em Projetos, Educação diferenciada para o século XXI. Porto Alegre: Penso, 2014.

BRASIL. Base Nacional Comum Curricular (BNCC). Educação é a Base. Brasília, MEC/ CONSED/UNDIME, 2017. Disponível em: http://basenacionalcomum.mec.gov.br/images/ BNCC_publicacao.pdf. Acesso em: 02 ago. 2018.

BRASIL. Lei no 13.005, de 25 de junho de 2014. Plano Nacional de Educação - PNE. Diário Oficial, Brasília, DF.

CALVO, A. H. Viaje a la escuela del siglo XXI - Así trabajan los colegios más innovadores del mundo. Fundação Telefônica: Madri, 2015.

DIAS, A. P. P. Ensino e aprendizagem intercultural de línguas estrangeiras: da teoria à sala de aula. In: SÁ, R. L. (org.). Português para falantes de outras línguas - interculturalidade, inclusão social e políticas linguísticas. Campinas: Pontes Editores, 2016.

GARCÍA MARTÍNEZ, A.; ESCARBAJAL FRUTOS, A.; ESCARBARAL DE HARO, A. (org.). La interculturalidad. Desafío para la educación. Madrid: Dykinson, 2007.

GROSSO, M. J.; SOARES, A.; SOUSA, F.; PASCOAL, J. 2011. Quadro de Referência para o Ensino Português no Estrangeiro. Disponível em: http://www.dgidc.minedu.pt/index. php?s=directorio\&pid=67. Acesso em: 13 jul. 2018.

HALL, S. Representation - Cultural Representations and Signifying Pratices. The Open University, 1997. 
LISPECTOR, C. A descoberta do mundo. Rocco: Rio de Janeiro, 1999.

MARCON, T. Multiculturalismo, intercultura e políticas educacionais. Revista Espaço Pedagógico, Passo Fundo, v. 16, n. 2, p. 48-61, jul./dez. 2009.

MARHAM, T.; LARMER, J.; RAVITZ, J. (org.). Buck Institute for Education. Porto Alegre: Artmed, 2008.

MEC/ SEF. Parâmetros Curriculares Nacionais: Ensino Fundamental. Brasília: MEC, Secretaria de Educação Básica, 1998.

MEC/ SEF. Parâmetros Curriculares Nacionais: terceiro e quarto ciclo: temas transversais: pluralidade cultural. Brasília: MEC, Secretaria de Educação Básica, 1998.

MEC/ SEF. Parâmetros Curriculares Nacionais: terceiro e quarto ciclo do ensino fundamental: língua estrangeira. Brasília: MEC, Secretaria de Educação Básica, 1998.

MEC/ SEB. Parâmetros Curriculares Nacionais: Ensino Médio. Brasília: MEC, Secretaria de Educação Básica, 2000.

MEC/SEB. Diretrizes Curriculares Nacionais dos cursos de Filosofia, História, Geografia, Serviço Social, Comunicação Social, Ciências Sociais, Letras, Biblioteconomia, Arquivologia e Museologia. Brasília: MEC, Secretaria de Educação Básica, 2001.

MEC/ SEB. Orientações Curriculares para o Ensino Médio. Linguagens, códigos e suas tecnologias. Conhecimentos de Línguas Estrangeiras; Conhecimentos de Espanhol. Brasília: MEC, Secretaria de Educação Básica, 2006.

MEC/SEB. Diretrizes Curriculares Nacionais da Educação Básica. Brasília: MEC, Secretaria de Educação Básica, 2013.

MENDES, E. Abordagem Comunicativa Intercultural (ACIN): uma proposta para ensinar e aprender língua no diálogo de culturas. 2003. Tese (Doutorado em Linguística) - Instituto de Estudos da Linguagem, Universidade Estadual de Campinas, Campinas, 2003.

PARAQUETT, M. Multiculturalismo, interculturalismo e ensino/aprendizagem de espanhol para brasileiros. In: BARROS, C. S.; COSTA, E. G. M. (org.). Coleção explorando o ensino Espanhol. Brasília: MEC, Secretaria de Educação Básica, 2010. p. 137-156. 